\title{
Investigasi Mode Shape akibat Flow Induced Vibration pada pipa sebagai fungsi Pola Aliran dan Jenis Tumpuan
}

\author{
I.M. Miasa ${ }^{1, *}$, Sucipto ${ }^{1}$, A. Wiranata ${ }^{1}$, S. Alfarizki ${ }^{1}$, N.C. Majid ${ }^{1}$ \\ 1Departemen Teknik Mesin dan Industri, Fakultas Teknik, Universitas Gadjah Mada \\ Jalan Grafik No. 2 Yogyakarta 55281 \\ Telp. 0274-521673 \\ e-mail: *1miasa@ugm.ac.id
}

\begin{abstract}
Abstrak
Sistem perpipaan sangat penting di dunia industri, khususnya industri yang berkaitan dengan fluida seperti industi minyak dan gas. Beberapa gangguan dalam suatu proses produksi atau distribusi sering terjadi akibat adanya permasalahan dalam sistem perpipaan. Salah satu masalah serius di dalam sistem perpipaan adalah getaran akibat aliran dari fluida (flow-induced vibration). Masalah getaran ini bila tidak ditangani secara benar akan menyebabkan kerusakan pada struktur sistem perpipaan dan komponen-komponen yang terkait seperti pompa atau mesin-mesin fluida lainnya. Pada penelitian ini, pengaruh dari karakteristik fluida dan jenis tumpuan pada pola getar (mode shape) akan diinvestigasi secara eksperimental. Karakteristik fluida dinyatakan dalam fraksi udara dan cairan. Dua jenis tumpuan pipa yaitu simply supported dan clamped supported secara detail diinvestigasi. Mode shape dari getaran pipa yang terjadi diukur sebagai fungsi dari karakteristik fluida dan jenis tumpuan. Hasil pengukuran secara eksperimental selanjutnya dibandingkan dengan hasil simulasi yang dilakukan dengan Finite Element Analysis. Hasil dari penelitian ini menunjukkan bahwa clamped support membuat pipa bergetar dengan frekuensi yang lebih tinggi, sedangkan aliran fluida dengan fraksi cairan yang lebih tinggi memberikan level getaran yang lebih tinggi.
\end{abstract}

Kata kunci: flow-induced vibration, mode shape, sistem perpipaan, jenis tumpuan.

\begin{abstract}
Piping systems are very important in industry, especially in industries related to fluids such as oil and gas industries. Some disturbances in a production or distribution process often occur due to problems in the piping system. One of the serious problems in piping systems is the flow-induced vibration. This vibration problem if not handled properly will cause damage to the structure of the piping system and related components such as pumps or other fluid machines. In this study, the influence of fluid characteristics and the type of support on the vibration pattern (mode shape) will be investigated experimentally. Fluid characteristics are expressed in air and liquid fractions. Two types of pipe support are simply supported and clamped supported in detail investigated. The shape mode of the pipe vibration that occurs is measured as a function of fluid characteristics and support type. The measurement results are experimentally then compared with the results of simulations conducted with Finite Element Analysis. The results of this study indicate that clamped support makes the pipe vibrate with a bigher frequency, while fluid flow with a higher liquid fraction provides a higher vibration level.
\end{abstract}

Keywords: flow-induced vibration, fashion shape, piping system, support type. 


\section{PENDAHULUAN}

Perpipaan merupakan bagian yang sangat vital bagi industri, khususnya industri yang berkaitan dengan fluida (minyak, gas, air dll). Sering ditemukan gangguan pada sebuah rangkaian proses produksi atau distribusi yang terjadi karena adanya masalah pada sistem perpipaan. Salah satu masalah yang sering tidak mendapat perhatian terkait sistem perpipaan adalah timbulnya getaran yang berlebih yang pada akhirnya akan merambat sampai ke tumpuan (support) pipa, pompa, atau ke mesin-mesin fluida lainnya. Beberapa laporan menyebutkan bahwa banyak kerusakan yang terjadi pada mesin-mesin fluida ternyata diawali dari getaran pipa yang luput dari perhatian pada saat melakukan perawatan. Permasalahan yang sama juga dijumpai pada sistem pipa yang digunakan untuk mendistribusikan fluida jarak jauh. Penelitian terkait getaran dari aliran fluida sudah cukup banyak dilakukan. Kajian yang mereview masalah-masalah flow induced vibration, khususnya di bidang pembangkit nuklir telah dilakukan oleh Paidoussis (2006). Sementara itu, Yakut dan Sahin (2004) melakukan analisa tentang flow-induced vibration dari conical rings yang digunakan untuk meningkatkan proses perpindahan panas pada sebuah heat exchanger. Pemasangan conical ring behasil meningkatkanproses perpindahan panas. Penelitian yang dilakukan oleh Faal dan Derakhshan (2011) menginvestigasi pengaruh dari tipe fondasi pipa, kecepatan dan densitas fluida, modulus elastisitas pipa dan panjang pipa terhadap getaran yang terjadi. Zhang dkk. (2010) melakukan kajian teoritis dan eksperimen terkait dampak internal turbulent bubbly flow pada getaran dari dinding sebuah saluran. Kajian komputasi power spectrum akibat interaksi struktur dan fluida turbulent sepanjang dinding dari sebuah elbow 900 telah dilaporkan oleh Hambric dkk. (2010). Sementara itu, Miasa dkk. (2010) melakukan kajian hubungan antara level getaran dengan kehandalan dari sebuah sistem pendukung proses pada sebuah industri pupuk. Pada penelitian ini, pengaruh dari karakteristik fluida dan jenis support pipa terhadap tingkat getaran yang muncul akan diinvestigasi secara eksperimental. Spektrum getaran yang timbul akan direkam dan dibandingkan dengan kajian Finite Element Analysis. Bervariasinya pola aliran, dan support pipa akan memberikan dampak atau paparan yang berbeda terhadap pipa yang dilalui fluida tersebut, yang pada akhirnya juga akan memberikan pola getaran yang berbeda pada pipa tersebut.

\section{METODE PENELITIAN}

Penelitian ini dijalankan dengan menggunakan beberapa variasi komposisi aliran fluida cair dan udara dengan variasi jenis support. Untuk komposisi aliran fluida cair, komposisi kecepatan yang digunakan antara $0,07-0,37 \mathrm{~m} / \mathrm{s}$ dan komposisi aliran fluida udara yang digunakan antara 3,7 - 6,17 m/s. Penelitian ini dilakukan dengan urutan sebagai berikut:

a. Pembuatan rangkaian pipa aliran dua fasa dan set up penelitian.

b. Pembuatan model finite element dan simulasi modal analysis dengan software ANSYS.

c. Pengukuran respon getaran dengan berbagai variasi aliran dan jenis tumpuan

d. Komparasi hasil simulasi dengan hasil pengukuran.

e. Analisa hasil hubungan antara komposisi aliran dengan spektrum getaran yang timbul.

Selengkapnya diagram alir penelitian dapat dilihat pada Gambar 1 di bawah ini. Sementara skema alat pengujian terlihat pada Gambar 2. 


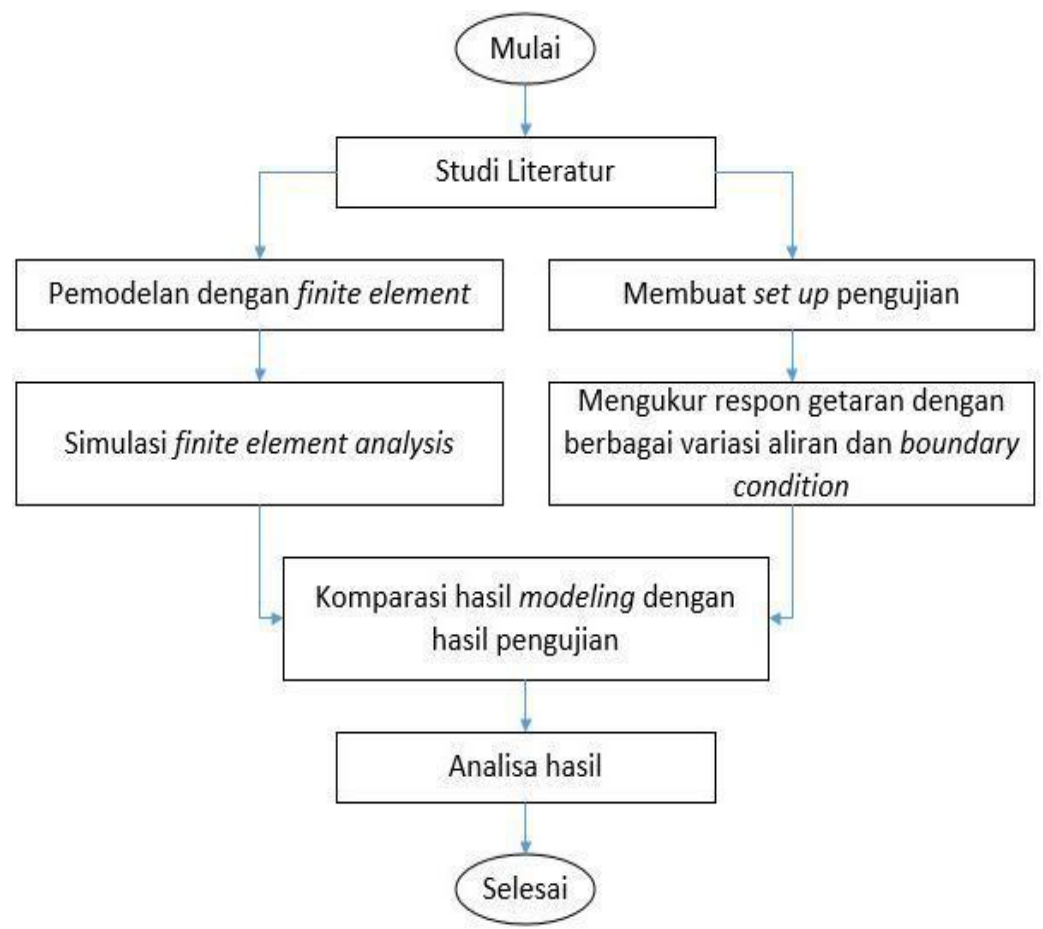

Gambar 1. Diagram alir penelitian

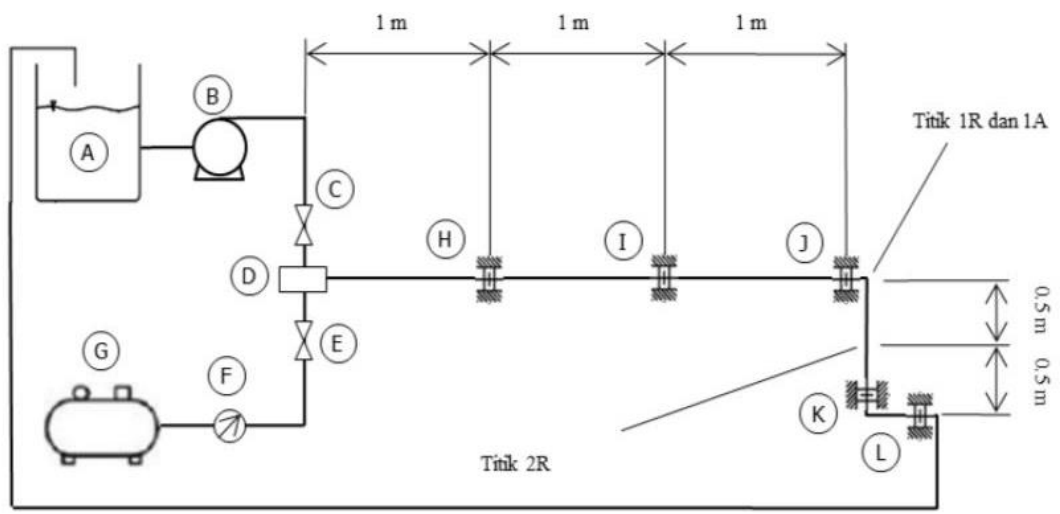

Gambar 2. Skema alat penelitian, (A) tangki air, (B) pompa air, (C) gate valve pengatur aliran air, (D) mixing chamber, (E) screw valve pengatur aliran udara, $(\mathrm{F})$ pressuer gange udara, $(\mathrm{G})$ kompresor udara,

$(\mathrm{H}, \mathrm{I}, \mathrm{J}, \mathrm{K}, \mathrm{L})$ posisi support.

Komposisi aliran yang digunakan dalam penelitian dapat dilihat pada Tabel 1 di bawah ini dengan $\mathrm{J}_{\mathrm{G}}$ dan $\mathrm{J}_{\mathrm{L}}$ masing-masing adalah kecepatan superfisial fluida udara dan fluida cair dalam $\mathrm{m} / \mathrm{s}$.

Tabel 1. Matriks Komposisi Aliran

\begin{tabular}{|c|c|c|}
\hline Komposisi & $\mathrm{J}_{\mathrm{G}}(\mathrm{m} / \mathrm{s})$ & $\mathrm{J}_{\mathrm{L}}(\mathrm{m} / \mathrm{s})$ \\
\hline 1 & 3,7 & 0,07 \\
\hline 2 & 3,7 & 0,22 \\
\hline
\end{tabular}




\begin{tabular}{|l|l|l|}
3 & 3,7 & 0,37 \\
\hline 4 & 6,17 & 0,07 \\
\hline 5 & 6,17 & 0,22 \\
\hline 6 & 6,17 & 0,37 \\
\hline
\end{tabular}

Masing-masing komposisi aliran tersebut di atas akan dilihat pengaruhnya pada area belokan pipa dengan dua jenis variasi support seperti terlihat pada Tabel 2 dibawah ini.

Tabel 2. Matriks variasi support.

\begin{tabular}{|c|c|c|}
\hline Variasi & Jumlah support & Jenis support \\
\hline 1 & 4 support & Clamped supported \\
\hline 2 & 4 support & Simply supported \\
\hline
\end{tabular}

\section{HASIL DAN PEMBAHASAN}

\section{Simulasi}

Hasil simulasi Finite Elemen untuk 5 mode awal untuk kondisi Clamped support disajikan pada Gambar 3-7. Sementara itu Gambar 8-12 menampilkan 5 mode shape dengan kondisi tumpuan Simply Supported.

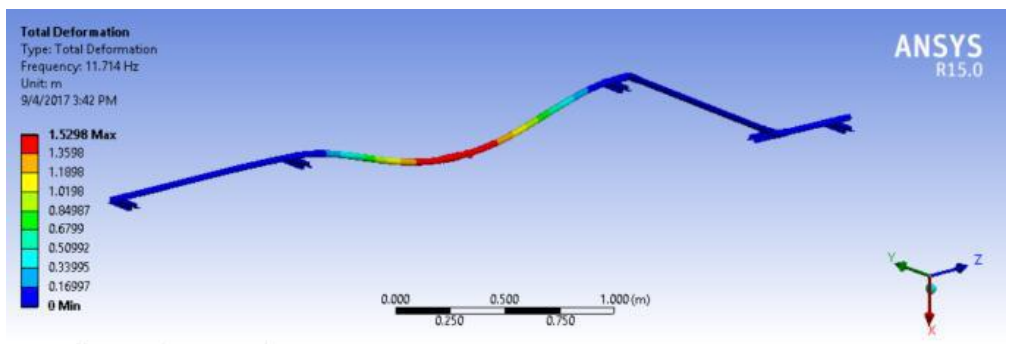

Gambar 3. Mode Shape \#1 Support \#1.

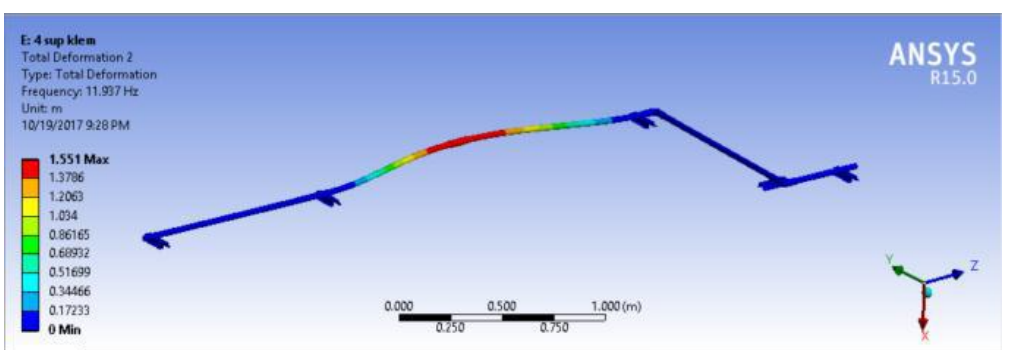

Gambar 4. Mode Shape \#2 Support \#1. 


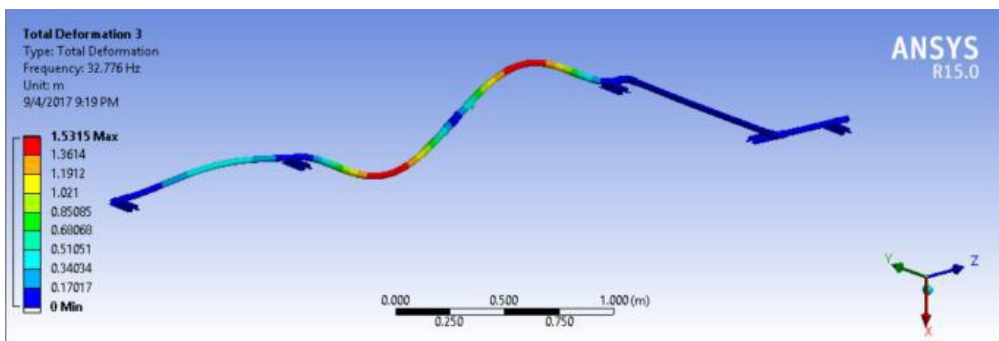

Gambar 5. Mode Shape \#3 Support \#1.

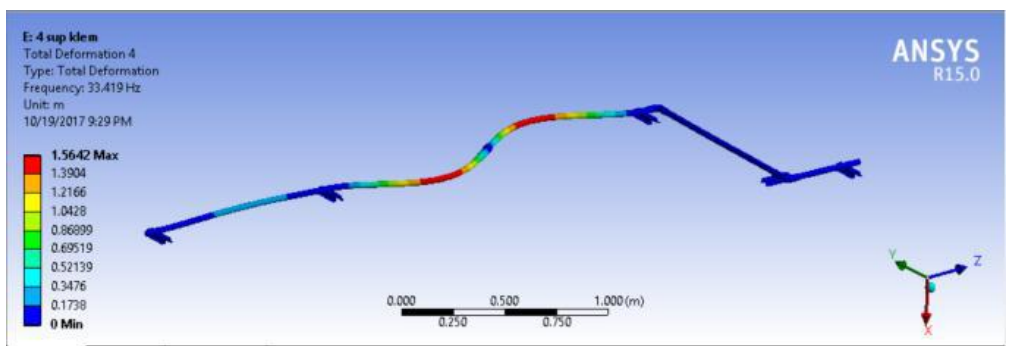

Gambar 6. Mode Shape \#4 Support \#1.

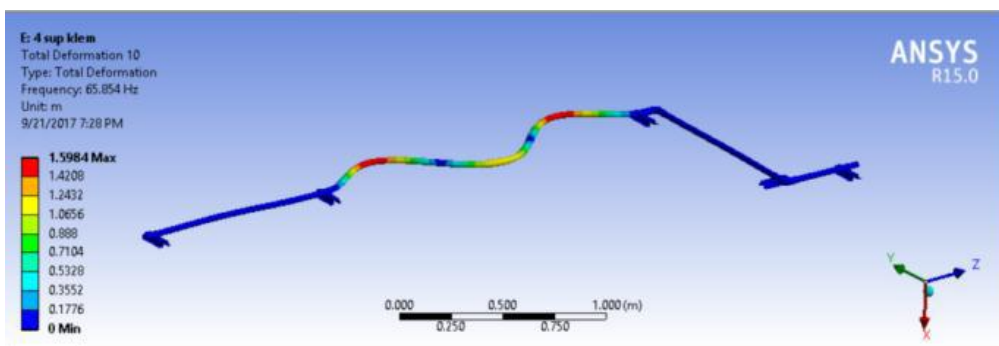

Gambar 7. Mode Shape \#10 Support \#1.

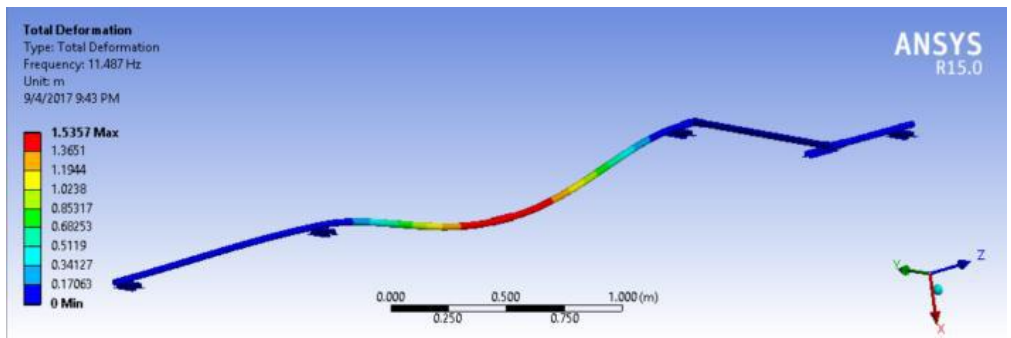

Gambar 8. Mode Shape \#1 Support \#2.

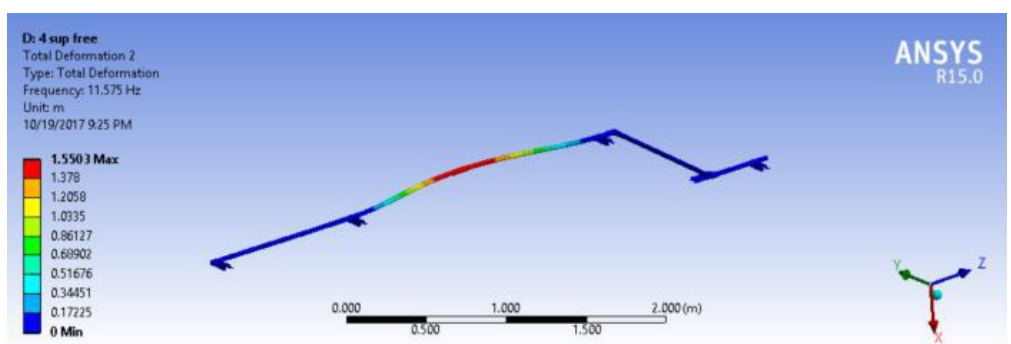

Gambar 9. Mode Shape \#2 Support \#2. 


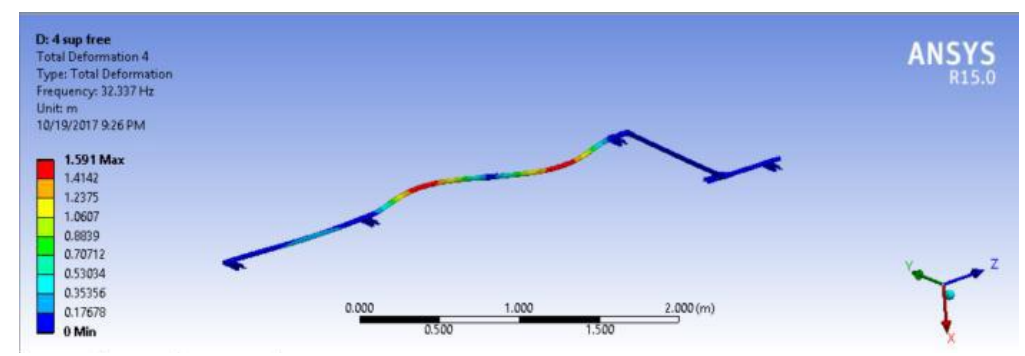

Gambar 10. Mode Shape \#3 Support \#2.

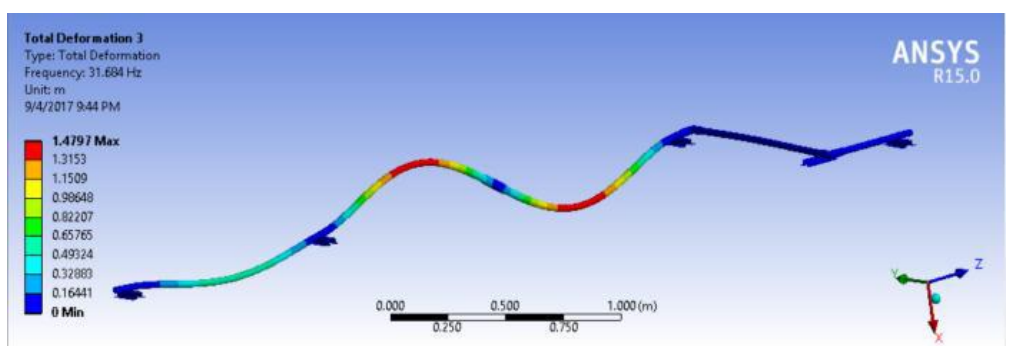

Gambar 11. Mode Shape \#4 Support \#2.

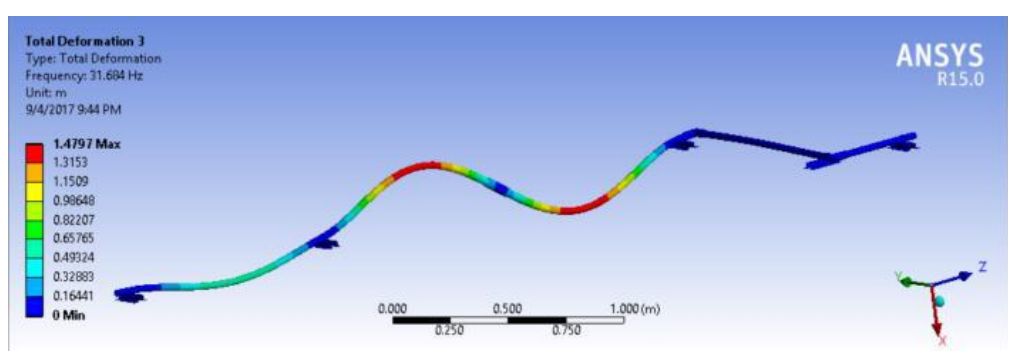

Gambar 12. Mode Shape \#10 Support \#2.

Tabel 3 menampilkan perbedaan nilai frekuensi alami dari jaringan pipa hasil simulasi dengan dua jenis support yang berbeda. Terlihat bahwa tumpuan jepit (clamped supported) memberikan nilai frekuensi yang lebih tinggi dibandingkan dengan nilai frekuensi pada kondisi simply supported.

Tabel 3. Perbandingan Frekuensi.

\begin{tabular}{|c|r|r|}
\hline \multirow{2}{*}{$\begin{array}{c}\text { Mode } \\
\text { ke }\end{array}$} & \multicolumn{2}{|c|}{ Frekuensi $(\mathrm{Hz})$} \\
\cline { 2 - 3 } & $\begin{array}{c}\text { Clamped } \\
\text { Supported }\end{array}$ & $\begin{array}{c}\text { Simply } \\
\text { Supported }\end{array}$ \\
\hline 1 & 11,78 & 11,49 \\
\hline 2 & 11,94 & 11,56 \\
\hline 3 & 32,79 & 31,64 \\
\hline 4 & 33,42 & 32,33 \\
\hline 10 & 65,85 & 63,75 \\
\hline 36 & 373,74 & 353,72 \\
\hline 38 & 391,99 & 371,61 \\
\hline
\end{tabular}




\begin{tabular}{|l|r|r|}
64 & 802,98 & 763,38 \\
\hline 65 & 827,15 & 773,78 \\
\hline
\end{tabular}

\section{Eksperimen}

Hasil pengukuran spektrum di area belokan dilakukan pada tiga titik pengukuran yaitu pada belokan arah radial (1R), belokan arah aksial (1A) dan titik berjarak $50 \mathrm{~cm}$ dari belokan arah radial (2R). Gambar 13-18 di bawah menunjukkan spectrum di titik pengukuran dengan komposisi aliran $3\left(\mathrm{~J}_{\mathrm{L}}=0,37 \mathrm{~m} / \mathrm{s}, \mathrm{J}_{\mathrm{G}}=6,17 \mathrm{~m} / \mathrm{s}\right)$ dan masing-masing dua variasi support berbeda. Hasil pengukuran dengan komposisi aliran yang berbeda juga menunjukkan trend yang hampir sama.

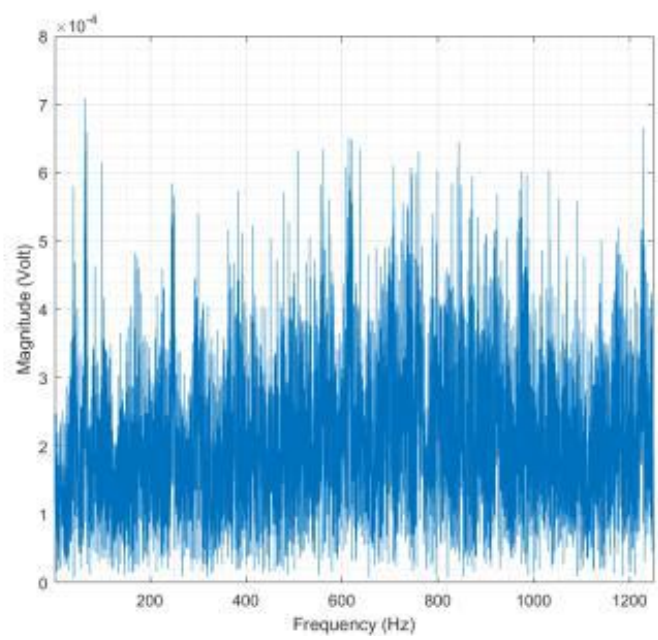

Gambar 13. Spektrum 1Radial Support 1.

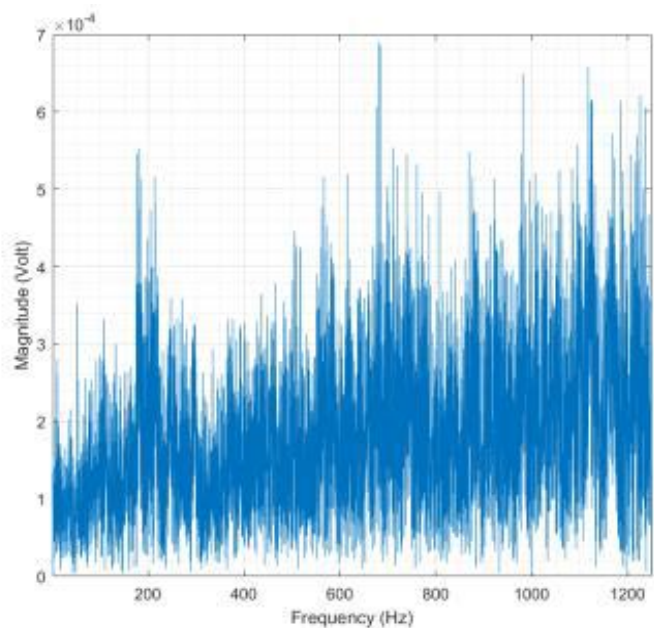

Gambar 14. Spektrum 1Aksial Support 1. 


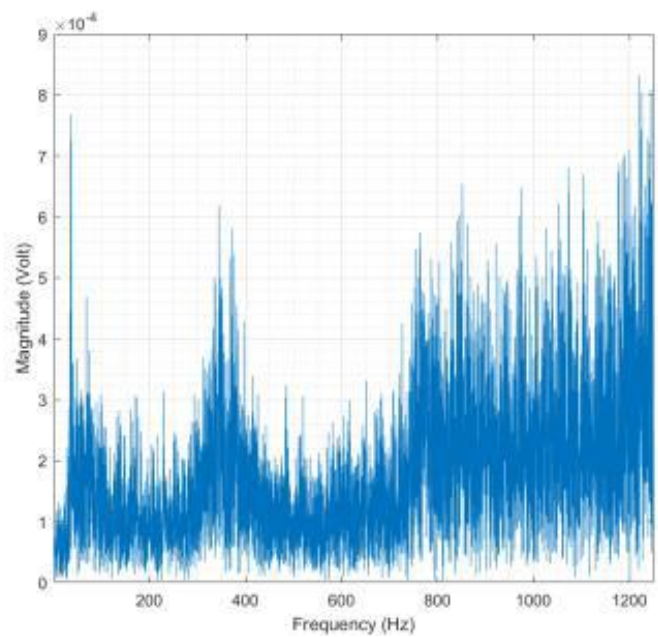

Gambar 15. Spektrum 2Radial Support 1.

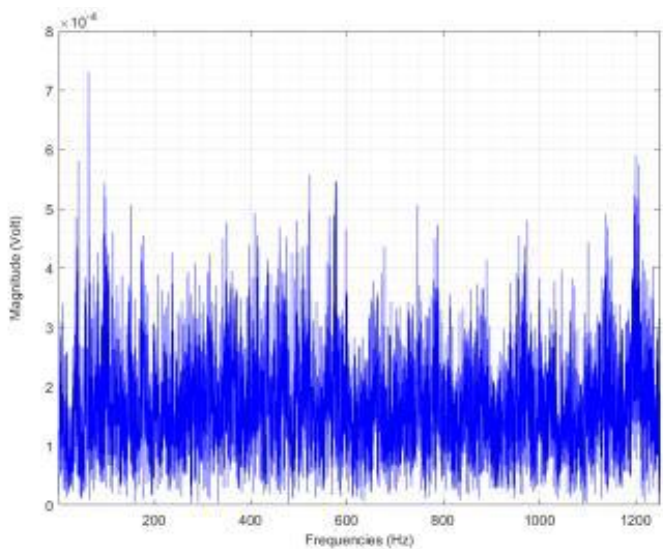

Gambar 16. Spektrum 1Radial Support 2.

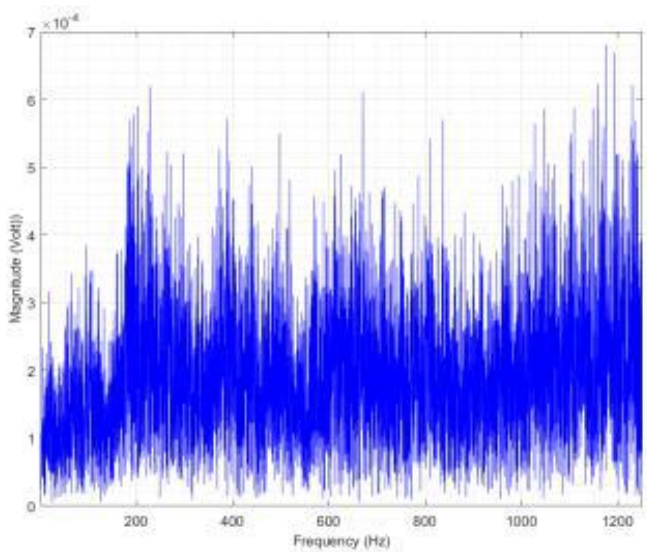

Gambar 17. Spektrum 1Aksial Support 2 


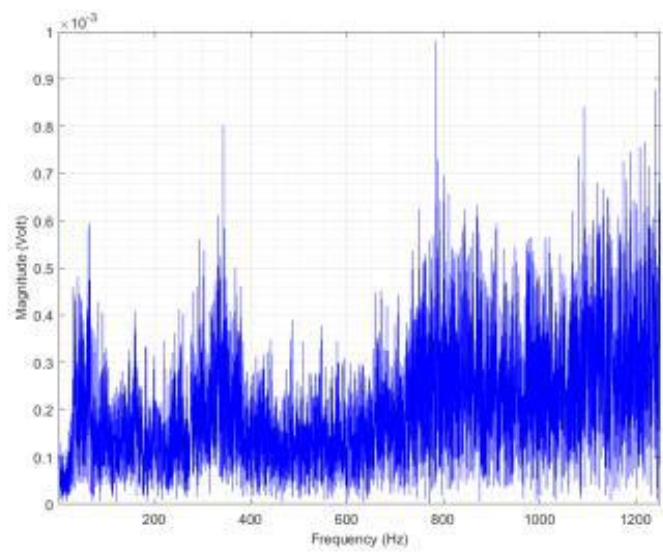

Gambar 18. Spektrum 2Radial Support 2.

Dari hasil pengukuran yang dilakukan, untuk komposisi aliran 3 di atas dan juga untuk komposisi aliran yang lain terlihat bahwa tidak terjadi pergeseran frekuensi yang signifikan akibat komposisi aliran yang berbeda-beda. Pengaruh perbedaan komposisi aliran terlihat lebih dominan terhadap perubahan level getaran di mana aliran dengan JL lebih besar memberikan level getaran yang lebih tinggi akibat lebih besarnya momentum yang dihasilkan. Pola spektrum yang hampir serupa juga dihasilkan dari kondisi support yang berbeda, dengan level getaran untuk kondisi simply supported lebih tinggi dari kondisi clamped supported.

\section{KESIMPULAN}

Dari penelitian ini, dapat disimpulkan bahwa kondisi clamped supported membuat sistem bergetar dengan frekuensi lebih tinggi. Sementara itu, komposisi aliran dengan fraksi cairan yang lebih besar menghasilkan level getaran yang lebih tinggi.

\section{DAFTAR PUSTAKA}

Faal, R. T., and Derakhshan, D., 2011, "Flow- Induced Vibration of Pipeline on Elastic Support", Procedia Engineering 14, 2986- 2993.

Hambric, S. A., Boger, D. A., Fahnline, J. B. and Campbell, R. L., 2010, "Structure- and fluidborne acoustic power sources induced by turbulent flow in $90^{\circ}$ piping elbows", Journal of Fluids and Stuctures 26, 121-147.

Miasa, I. M., Purwanto, T. P. and Erliandy, L., 2010, "Vibration and reliability of synthesis gas compressors (A case study in PKT-Kaltim Indonesia)", Proceedings of the 20th International Congress on Acoustics, Sydney, Australia.

Paidoussis, M. P., 2006. "Real life experiences with flow-induced vibration", Journal of Fluids and Structures 22, $741-755$.

Yakut, K. and Sahin, B., 2004, "Flow-induced vibration analysis of conical rings used for heat transfer enhancement in heat exchangers", Applied Energy 78, 273-288.

Zhang. M. M., Katz, J. and Prosperetti, A., 2010, "Enhancement of channel wall vibration due to acoustic excitation of an internal bubbly flow", Journal of Fluids and Structures 26, 994-1017. 